\title{
Smouldering Combustion of Solid Bulk Materials at Different Volume Fractions of Oxygen in the Surrounding Gas
}

\author{
MARCUS MALOW ${ }^{1}$ and ULRICH KRAUSE ${ }^{2}$ \\ ${ }^{1}$ Division II.2 "Reactive substances and systems" \\ ${ }^{2}$ Division VII.3 "Fire Engineering" \\ Federal Institute for Materials Research and Testing (BAM) \\ Unter den Eichen 87, 12205 Berlin, Germany
}

\begin{abstract}
:
Fires in storage facilities of bulk goods, recycling materials, granules or dusts are mostly smouldering or glowing fires producing large amounts of gases which are released to the environment. Many of these fires are due to preceding self-ignition of the material. The current paper presents investigations on lab-scale on the influence of the volume fraction of oxygen in the gas surrounding the bulk material on the reaction temperatures, the mass loss and the composition of the flue gas during smouldering fires triggered by selfignition. This reflects the conditions present e.g. in silo fires, where the access of oxygen to the reaction zone is hampered.
\end{abstract}

The composition of gaseous reaction products was measured using FTIR spectroscopy, the mass loss of the solid fraction during the combustion was observed using a thermogravimetric scale.

It was found that the volume fraction of oxygen significantly changes reaction temperatures, the rate of mass loss and the composition of the flue gas.

KEYWORDS: bulk materials, smouldering, self-heating, self-ignition

NOMENCLATURE LISTING:

$\begin{array}{ll}\mathrm{T} & \text { Temperature } \\ \mathrm{T}_{\text {core }} & \text { Temperature in the centre of the sample } \\ \mathrm{T}_{1 / 2 \text { Radius }} & \text { Temperature at half the distance between centre of the sample and surface } \\ \mathrm{T}_{\text {oven }} & \text { Temperature in the oven atmosphere } \\ \mathrm{X} & \text { volume fraction of gas component }\end{array}$

\section{INTRODUCTION}

Fire fighting in large storage facilities is always a big challenge. Large masses of flammable materials involved in the fire, huge emissions of heat, smoke and potentially harmful gases, questions about the static integrity of the structure and awkward access to the fire sites lead to extensive, difficult, risky, timeconsuming and costly fire fighting actions. Therefore the main focus should always be on preventing such fires. However, if prevention is not successful, it is important to know reaction temperatures, reaction rates and the composition of the relevant components of the flue gas released by such fires. These quantities mainly depend on the availability of oxygen in the reaction zone. A significant number of such fires occurs due to self-ignition.

Some relevant case studies of fires of bulk materials in storage facilities like silos were given by Eckhoff [1], Humez [2] and Westermann [3]. Common features in such fires are

- an excessive release of smoke,

- incomplete combustion,

- reaction temperatures between $250{ }^{\circ} \mathrm{C}$ to $500{ }^{\circ} \mathrm{C}$ (smouldering fire) or $500{ }^{\circ} \mathrm{C}$ to $800{ }^{\circ} \mathrm{C}$ (glowing fire) depending on the availability of oxygen,

- besides the production of $\mathrm{CO}_{2}$ and $\mathrm{H}_{2} \mathrm{O}$, significant production of $\mathrm{CO}$ and $\mathrm{CH}_{4}$. 
It does not need to be explained that the volume fraction of oxygen in the gas passing through a porous combustible material plays a key role for the reaction rate of the oxidation. Limiting the supply of oxygen to the active surfaces of the solid matter abates the reaction considerably. However, the rate of oxygen consumption during self-ignition is low and the question arises at which content of oxygen in the gas passing through a dust accumulation self-ignition may be suppressed effectively.

An early investigation on the role of oxygen during self-ignition was undertaken by Bowes and Thomas [4]. They reported self-ignition temperatures at volume fractions of oxygen between 4 and $30 \%$. The material under investigation was hardwood saw dust, the sample volumes ranged from $15.6 \mathrm{~cm}^{3}$ to $439 \mathrm{~cm}^{3}$. Bowes and Thomas found that the self-ignition temperatures increased with reduced oxygen level and decreased for increased oxygen content. Moreover, plotting the results in an Arrhenius diagram they found that the apparent activation energy remained the same for different oxygen fractions. A tentative conclusion from these findings was, that the reaction mechanism remained more or less the same independently of the oxygen content.

The influence of the volume fraction of oxygen on self-ignition temperatures of dusts and bulk materials in basket tests was also reported by Schmidt, Lohrer and Krause [5]. They showed that reducing the volume fraction of oxygen in the gas surrounding the bulk material significantly increases the self-ignition temperatures but cannot prevent self-ignition itself until volume fractions of oxygen as low as about $2 \%$.

It is well known that moisture effects self-ignition in two ways: on the one hand the vaporisation of moisture consumes energy and hence the ignition process is impeded. On the other hand a promotion of self-ignition by wetting of materials prone to self-ignition has experimentally been observed, see Gray and Wake [6], Gray et.al. [7] and Chon and Chen [8]. This effect is attributed to the heat of adsorption when stockpiled material is wetted and to the heat of condensation when the stockpile is in a humid or damp environment. Gray et.al. [7], for example, could show that a thermally stable stockpile of bagasse can become critical when the humidity of the ambient air is increased. This kind of behaviour is not covered by the usual small-size high-temperature hot storage tests, because in these tests the oven temperature is usually beyond the boiling point of water at ambient pressure. However, the conclusions drawn by Gray et.al. give an explanation for the observation made under practical conditions, that deposits of dry solid bulk materials may ignite at storage temperatures well below the critical temperatures as predicted by extrapolating hot storage tests when exposed to humid air.

For some materials, e.g. hay or other biomass biological activity - influenced by humidity - may increase the internal temperature of the stored mass up to about $70^{\circ} \mathrm{C}$ and hence, be a precursor of oxidation. This phenomenon is also not covered by hot storage testing.

The present study deals with the influence of the volume fraction of oxygen in the surrounding gas on the reaction temperature the mass loss and the composition of the gaseous reaction products during combustion of bulk materials on a laboratory-scale. The experiments were intended to reflect the conditions e.g. in a silo where the access of oxygen to the reaction zone may be restricted by non-permeable silo walls, sealing of openings or by the limited convective flux of air through the porous layer of bulk material around the reaction zone. (Recently, in Germany silos of up to $100000 \mathrm{t}$ of capacity have been erected for storage of black coal to reduce dust emissions resulting from storage in open heaps.)

Though the fires were all initiated by self-ignition, the focus of the paper lies on the features of fire propagation after ignition and not on the self-ignition itself. The influence of humidity or biological activity on the self-ignition process was out of the scope of this paper. All test samples were dried to a moisture content below $5 \%$ in mass before the experiments.

Basket tests in a laboratory oven were undertaken for wood chips, recycling material, black coal and lignite coal. The temperatures evolution within the sample was measured simultaneously with the sample mass and the volume fractions of $\mathrm{CO}, \mathrm{CO}_{2}, \mathrm{H}_{2} \mathrm{O}$ and $\mathrm{CH}_{4}$ in the flue gas.

\section{SMOULDERING COMBUSTION EXPERIMENTS}

Smouldering combustion experiments were performed for some materials typically stored in silos, namely wood chips, lignite coal and black coal. In addition, recycling material intended for use as substitute fuel in heating stations was considered. This material was a mixture of shredded residues of plastic wrappings, foils, textile floorings, cotton rags etc. Material properties are given in table 1. 
Table 1. Properties of materials under investigation

\begin{tabular}{|c|c|c|c|c|}
\hline & Wood chips & Recycling material & Black coal & Lignite coal \\
\hline Particle size in mm & $<1$ & $<1$ & $<10$ & $<8$ \\
\hline Bulk density in $\mathrm{kg} / \mathrm{m}^{3}$ & 402 & 200 & 742 & 568 \\
\hline Calorific value in J/g & 18525 & 35447 & 20161 & 33870 \\
\hline $\begin{array}{c}\text { Thermal conductivity in W/mK } \\
\text { Self-ignition temperature at V }=400 \mathrm{~mL} \text { and } 21 \% \\
\mathrm{O}_{2} \text { in }{ }^{\circ} \mathrm{C}\end{array}$ & 0.0839 & 0.0676 & 0.103 & 0.11 \\
\hline
\end{tabular}

To reflect the conditions during smouldering combustion in a silo, the oven was flushed with mixtures of nitrogen and oxygen of different compositions. By this, mass loss rates, reaction temperatures and volume fractions of different components contained in the flue gas could be measured in dependence on the oxygen content.

The experimental set-up was described in detail by Poyda [9]. It consisted of a laboratory oven as normally used for basket tests, which was modified in the following way:

- An inner chamber of about $40 \mathrm{l}$ in volume was inserted to control the flux rate of the oxygen/nitrogen mixture of the desired composition.

- A thermogravimetric scale was adopted to measure the mass loss of the bulk sample.

- The exhaust gas was directed to a Fourier-Transform infrared spectrometer for gas analysis.

The experimental set-up is shown in Fig. 1.

All experiments were performed with samples of $400 \mathrm{~mL}$ in volume being stored in a cylindrical basket with equal height and diameter.

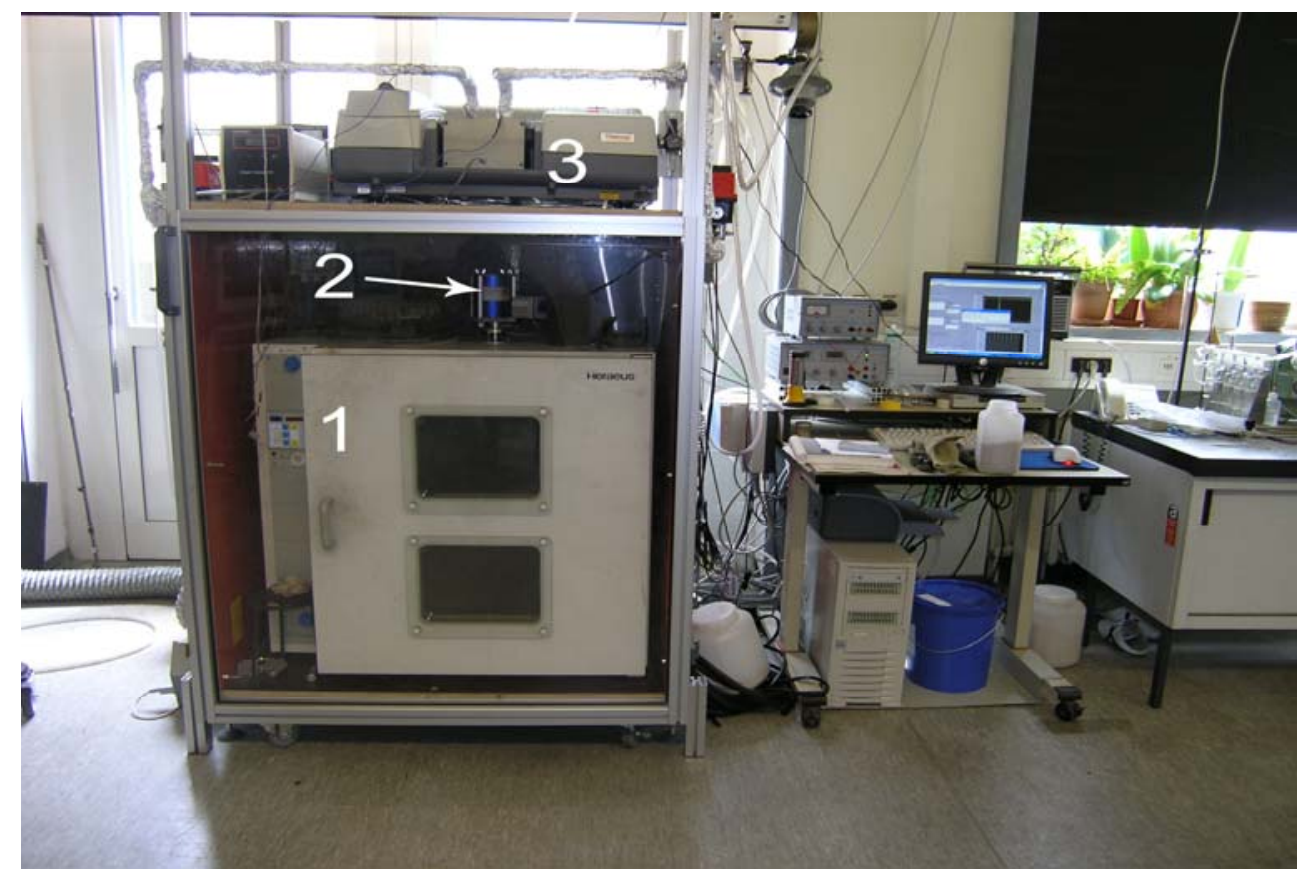

Fig. 1. Laboratory oven (1) for investigating the self-ignition and smouldering propagation of bulk materials with thermogravimetric scale (2) and FTIR spectrometer (3) 
The thermogravimetric scale works in the following way: The sample holder hangs at a hook which is attached to an oscillating tungsten wire. The frequency of oscillations is a measure for the weight of the sample. By this a quasi-continuous signal of the sample mass can be acquired. In contrast to other thermogravimetric systems, where the sample mass is limited to a few grams, samples of up to $500 \mathrm{~g}$ can be treated.

Using the FTIR spectroscopy, volume fractions of $\mathrm{CO}, \mathrm{CO}_{2}, \mathrm{H}_{2} \mathrm{O}, \mathrm{CH}_{4}$ and $\mathrm{NH}_{3}$ could be determined quantitatively. Other chemical species could be identified qualitatively.

Thermocouples were placed in the centre of the sample (" $T_{\text {core" }}$ in the diagrams) and at half of the distance

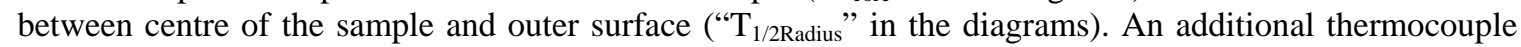
was located in the gas atmosphere within the inner chamber of the oven.

Table 2 gives an overview of the experiments undertaken. The oven temperatures were selected to be somewhat higher than the corresponding self-ignition temperatures to certainly trigger a smouldering fire. The volume flux rates of the nitrogen/oxygen mixtures were selected such that the flow velocity inside the inner chamber was minimal, however, without suffocating the fire.

Table 2: Experimental parameters for smouldering fire experiments with variation of the volume fraction of oxygen.

\begin{tabular}{|c|c|c|c|c|c|c|}
\hline Wood chips & Exp. 1 & Exp. 2 & Exp. 3 & Exp. 4 & Exp. 5 & Exp. 6 \\
\hline $\begin{array}{l}\mathrm{X}_{\mathrm{O} 2} \text { in Vol- } \\
\%\end{array}$ & 3.6 & 6 & 7.8 & 11.4 & 15 & 21 \\
\hline $\mathrm{T}_{\text {Oven }}$ in ${ }^{\circ} \mathrm{C}$ & 203 & 203 & 203 & 203 & 203 & 203 \\
\hline$\dot{\mathrm{V}}$ in $\mathrm{l} / \mathrm{h}$ & 100 & 100 & 100 & 100 & 100 & 100 \\
\hline $\begin{array}{l}\text { Recyling } \\
\text { material }\end{array}$ & Exp. 1 & Exp. 2 & Exp. 3 & Exp. 4 & Exp. 5 & Exp. 6 \\
\hline $\begin{array}{l}\mathrm{X}_{\mathrm{O} 2} \text { in Vol- } \\
\%\end{array}$ & 3.2 & 5.5 & 8.7 & 11.6 & 15 & 21 \\
\hline $\mathrm{T}_{\text {Oven }}$ in ${ }^{\circ} \mathrm{C}$ & 203 & 203 & 203 & 203 & 203 & 203 \\
\hline$\dot{\mathrm{V}}$ in $\mathrm{l} / \mathrm{h}$ & 100 & 100 & 100 & 100 & 100 & 100 \\
\hline Black coal & Exp. 1 & Exp. 2 & Exp. 3 & Exp. 4 & Exp. 5 & - \\
\hline $\begin{array}{l}\mathrm{X}_{\mathrm{O} 2} \text { in Vol- } \\
\%\end{array}$ & 5.5 & 6 & 11.6 & 15 & 21 & - \\
\hline $\mathrm{T}_{\text {Oven }}$ in ${ }^{\circ} \mathrm{C}$ & 252 & 234 & 234 & 234 & 234 & - \\
\hline$\dot{\mathrm{V}}$ in $\mathrm{l} / \mathrm{h}$ & 100 & 100 & 100 & 100 & 100 & - \\
\hline Lignite coal & Exp. 1 & Exp. 2 & Exp. 3 & Exp. 4 & Exp. 5 & - \\
\hline $\begin{array}{l}\mathrm{X}_{\mathrm{O} 2} \text { in Vol- } \\
\%\end{array}$ & 3.5 & 6.7 & 10.8 & 15 & 21 & - \\
\hline $\mathrm{T}_{\text {Oven }}$ in ${ }^{\circ} \mathrm{C}$ & 196 & 196 & 196 & 196 & 196 & - \\
\hline$\dot{\mathrm{V}}$ in $\mathrm{l} / \mathrm{h}$ & 100 & 100 & 100 & 100 & 100 & - \\
\hline
\end{tabular}

\section{EXPERIMENTAL RESULTS}

The first experiments to be discussed here were undertaken with wood chips and an air flux of $100 \mathrm{l} / \mathrm{h}$. The course of this experiment can be considered as typical for a self-ignition process in air. Figure 2 shows the evolution with time of the temperatures in the sample core and at half of the radius, of the mass loss and of the volume fractions of $\mathrm{CO}, \mathrm{CO}_{2}, \mathrm{H}_{2} \mathrm{O}$ and $\mathrm{CH}_{4}$. During the heating period the core temperature $\mathrm{T}_{\text {core }}$ follows the temperature at half the radius $\mathrm{T}_{1 / 2 \text { Radius }}$ with a delay mainly caused by the vaporisation of the moist contained in the wood chips. At the time $\mathrm{T}_{\text {core }}$ and $\mathrm{T}_{1 / 2 \text { Radius }}$ crossed $\mathrm{T}_{\text {oven }}$, a significant release of 
gaseous reaction products out of the sample is noticed with $\mathrm{CO}_{2}$ being detected earliest followed by $\mathrm{H}_{2} \mathrm{O}$, $\mathrm{CO}$ and $\mathrm{CH}_{4}$.

The experiments did not indicate transition to a glow fire. The sudden drop of the $\mathrm{T}_{\text {core }}$ after $450 \mathrm{~min}$ was due to shrinking of the sample with the thermocouple hanging freely in the sample holder.

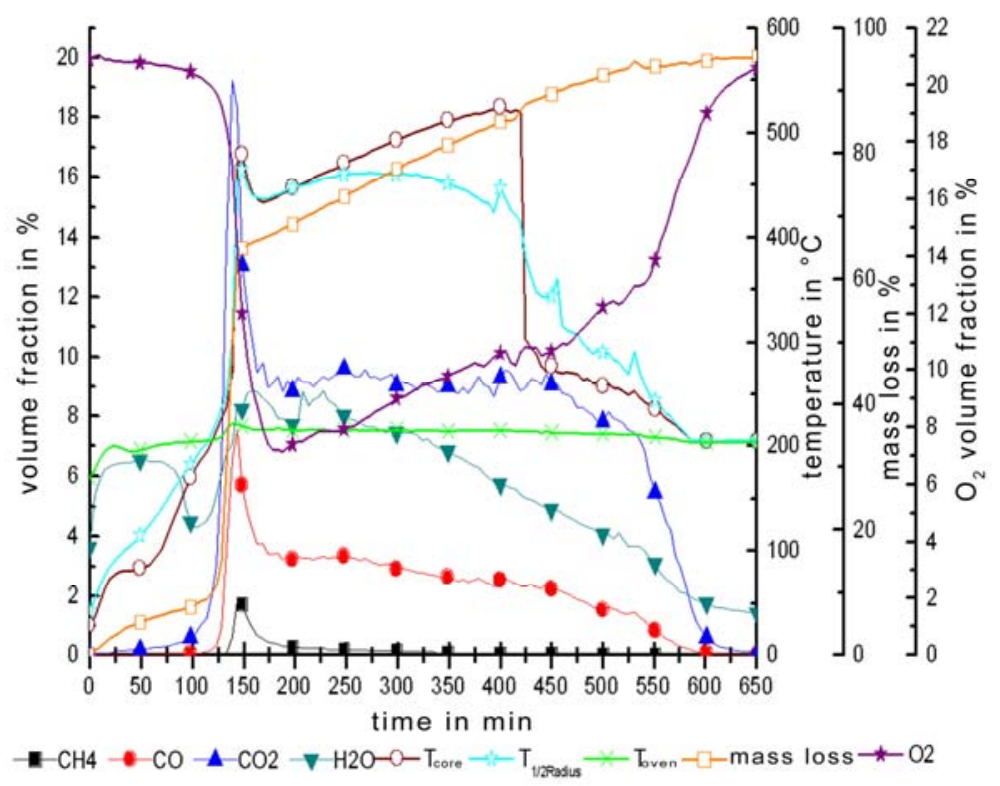

Fig. 2. Evolution with time of core temperature, temperature at half the radius, mass loss and volume fractions of $\mathrm{CO}, \mathrm{CO}_{2}, \mathrm{H}_{2} \mathrm{O}$ and $\mathrm{CH}_{4}$ during self-ignition and combustion of a $400 \mathrm{~mL}$ sample of wood chips in air (Symbols are not measured values but are intended to discriminate the different curves.)

A significant mass loss of the sample was detected from the beginning of the experiment due to vaporisation of water, while a rapid increase appeared in coincidence with the increase in temperature and volume fraction of $\mathrm{CO}_{2}$, i.e. when the self-ignition started. The level of temperatures reached during the

Figure 3 shows a comparison of the curves for $T_{\text {core }}$ at different volume fractions of oxygen. While for oxygen concentrations higher than $11 \%$ obviously the state of glowing was reached, below this value the temperature reached a level typical for a smouldering process.

In addition, the experiments showed that the lower the oxygen fraction was the longer was the reaction time. However, even an oxygen volume fraction of $3.6 \%$ was not sufficient to suppress smouldering.

Figure 4 exhibits the evolution with time of the ratio of volume fractions of $\mathrm{CO}$ to $\mathrm{CO}_{2}$ in dependence on the volume fraction of oxygen for the self-ignition and subsequent combustion of wood chips.

As expected, a relatively high $\mathrm{CO} / \mathrm{CO}_{2}$ ratio between 0.3 and 0.4 is maintained over the entire reaction time for oxygen fractions below $11 \%$, where smouldering occurs. For oxygen fractions above this level, where a glowing combustion was predominant, the $\mathrm{CO} / \mathrm{CO}_{2}$ ratio after the self-ignition and the onset of reaction propagation drops down to about 0.1 .

The corresponding overall mass losses during the experiments were between $40 \%$ for an oxygen fraction in the flushing gas of $3.6 \%$ and $95 \%$ for an oxygen fraction of $21 \%$.

Figure 5 shows a comparison of the temperature-time curves obtained for recycling material and different volume fractions of oxygen in the surrounding of the sample. The core temperatures are generally lower than observed for wood chips. The explanation is that lignine as the basic component of wood contains chemically bound oxygen which is released under the action of heat and contributes to the combustion.

In addition a fraction of the recycling material melts under the influence of heat forming lumps of molten material which do not take part in the smouldering process. Hence, the release of heat is much lower than observed for the wood chips. (Despite, however, the calorific value is much higher than for wood chips.) 


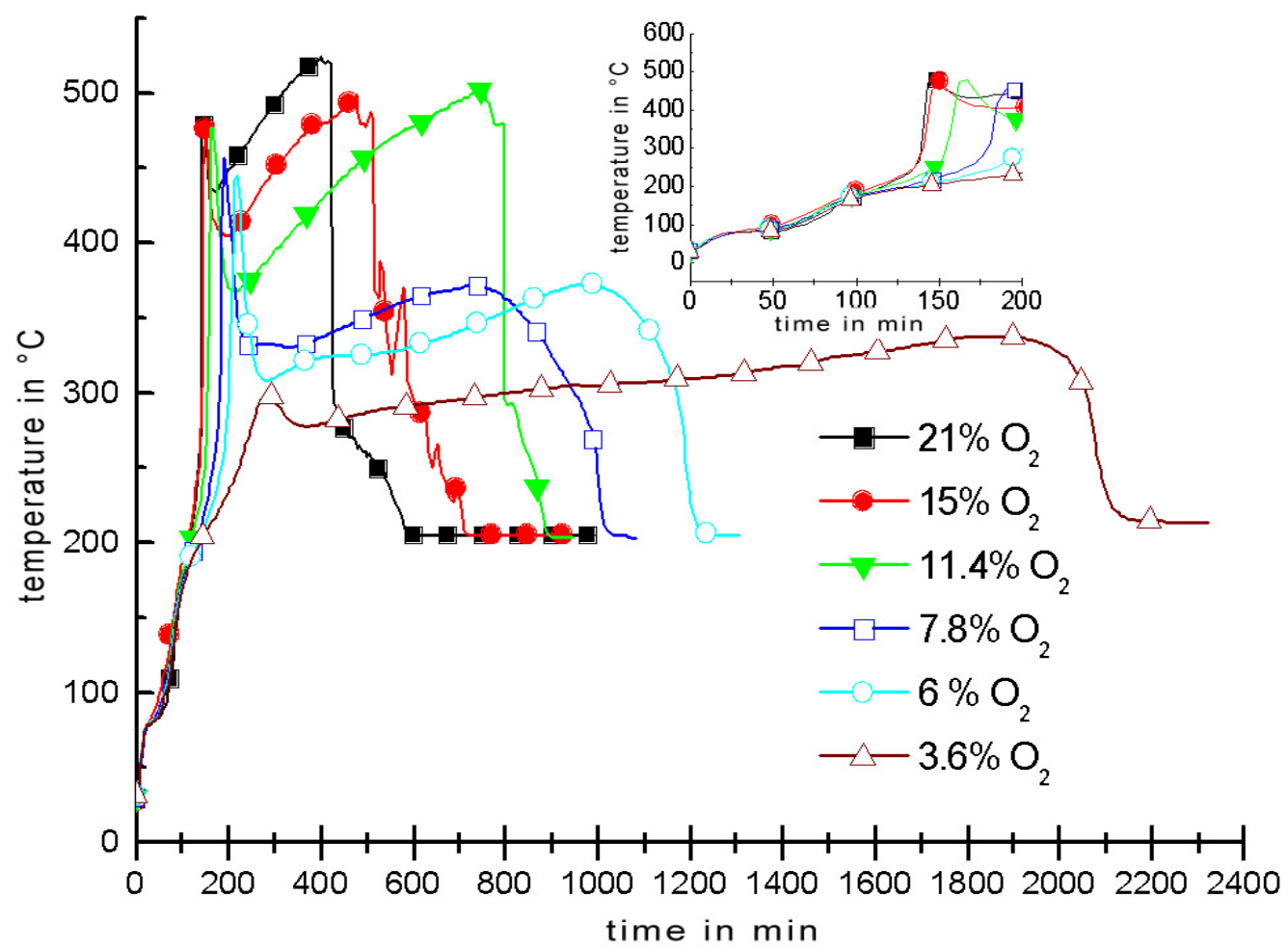

Fig.3 Evolution of the temperature in the core of the $400 \mathrm{~mL}$ sample with time during self-ignition of wood chips at different volume fractions of oxygen in the surrounding (The incremental diagram expands the first $200 \mathrm{~min}$. Symbols are not measured values but are intended to discriminate the different curves.)

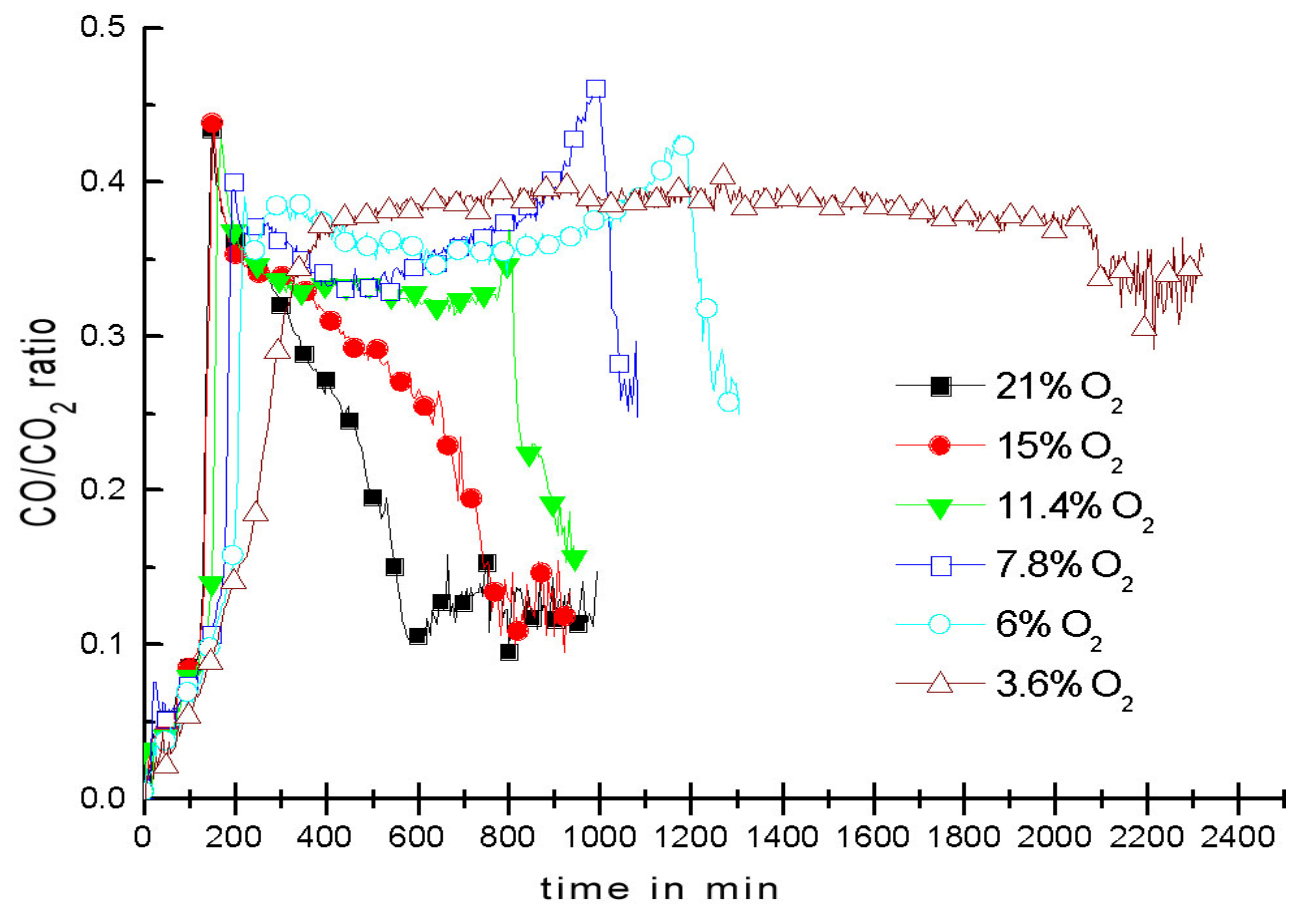

Fig. 4. Ratio of volume fractions of $\mathrm{CO}$ and $\mathrm{CO}_{2}$ for the combustion of $400 \mathrm{~mL}$ samples of wood chips at different volume fractions of oxygen in the surrounding (Symbols are not measured values but are intended to discriminate the different curves). 


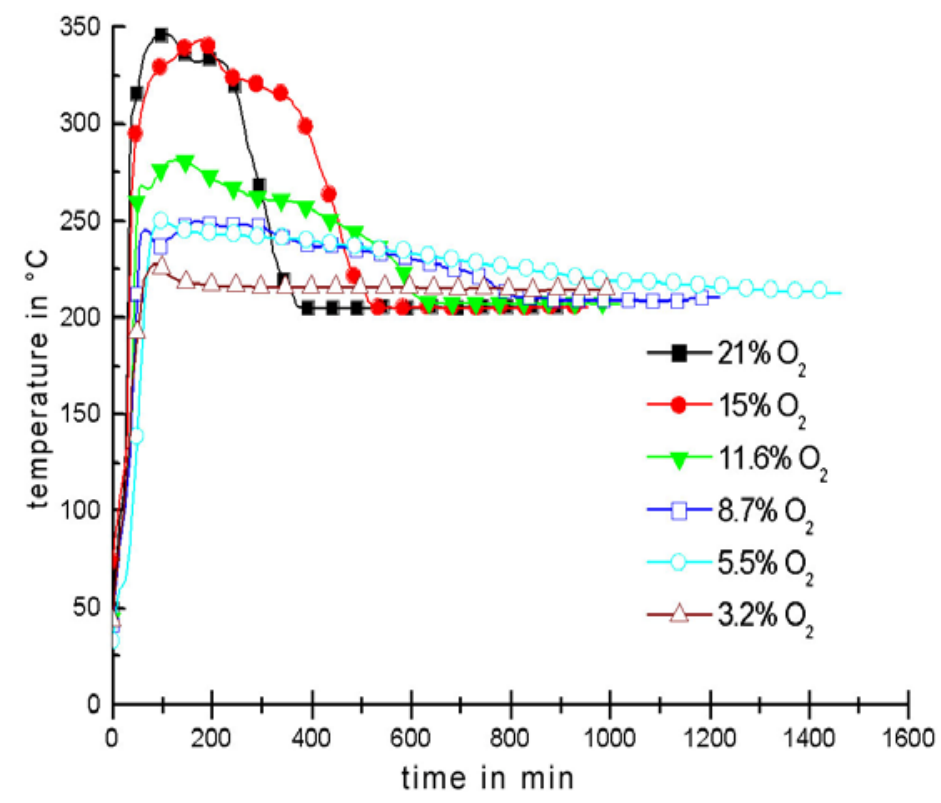

Fig. 5. Evolution of the temperature in the core of the $400 \mathrm{~mL}$ sample with time during self-ignition of recycling material at different volume fractions of oxygen in the surrounding and at an oven temperature of

$203^{\circ} \mathrm{C}$. (Symbols are not measured values but are intended to discriminate the different curves.)

Figure 6 depicts the corresponding ratios of volume fractions of $\mathrm{CO}$ to $\mathrm{CO}_{2}$ for the recycling material. Due to the lack of oxygen in the sample immediately after the onset of combustion (e.g. after 27 minutes for 21 $\%$ of surrounding oxygen), even more $\mathrm{CO}$ than $\mathrm{CO}_{2}$ was produced.

It has to be mentioned that for a volume fraction of oxygen in the gas mixture flushing the oven of $3.6 \%$ the mass loss was $10 \%$ while it was $60 \%$ for an oxygen volume fraction of $21 \%$.

In Fig. 7 the temperature-time curves for samples of black coal are depicted. In contrast to the previous experiments the oven temperature here was elevated to $234^{\circ} \mathrm{C}$ since $203{ }^{\circ} \mathrm{C}$ was below the self-ignition temperature of the $400 \mathrm{~mL}$ sample of black coal. Exothermicity was only observed for oxygen volume fractions higher than $11 \%$. For an oxygen concentration of $5.5 \%$ the oven temperature was increased to $252{ }^{\circ} \mathrm{C}$ which lead to an increase of the sample temperature to $300{ }^{\circ} \mathrm{C}$.

The overall mass loss was $55 \%$ for the sample flushed with air and $8 \%$ for the one flushed with the mixture containing $6 \%$ oxygen. For the sample flushed with $5.5 \%$ oxygen and stored at $252{ }^{\circ} \mathrm{C}$ the mass loss was $12 \%$.

The ratio of volume fractions of $\mathrm{CO} / \mathrm{CO}_{2}$ is shown in fig.8. In general, the mass loss per time - as a measure for the reaction rate - was much lower for the black coal than for the wood chips and the recycling material. Surprisingly, the ratio of volume fractions of $\mathrm{CO}$ to $\mathrm{CO}_{2}$ was highest when the sample was flushed with air.

A possible explanation may be that in this case the reaction rate (indicated by the mass loss per time) and, hence, the consumption of oxygen was highest. No explanation could be found for the peak in the $\mathrm{CO} / \mathrm{CO}_{2}$ ratio appearing for $21 \%$ oxygen after 3300 minutes, since at this time neither an alteration of the temperature (see Fig. 7) nor of the mass loss (not depicted) were observed. 


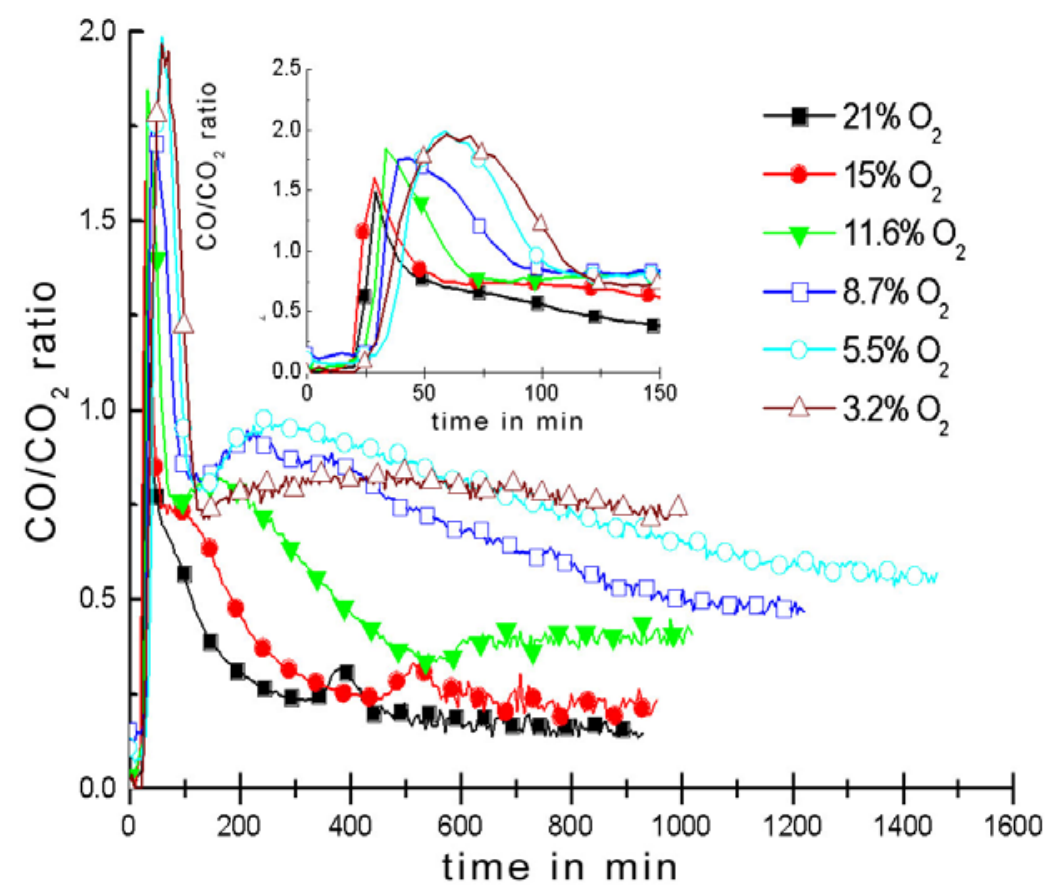

Fig. 6. Ratio of volume fractions of $\mathrm{CO}$ and $\mathrm{CO}_{2}$ for the combustion of $400 \mathrm{~mL}$ samples of recycling material at different volume fractions of oxygen in the surrounding and at an oven (Symbols are not measured values but are intended to discriminate the different curves.)

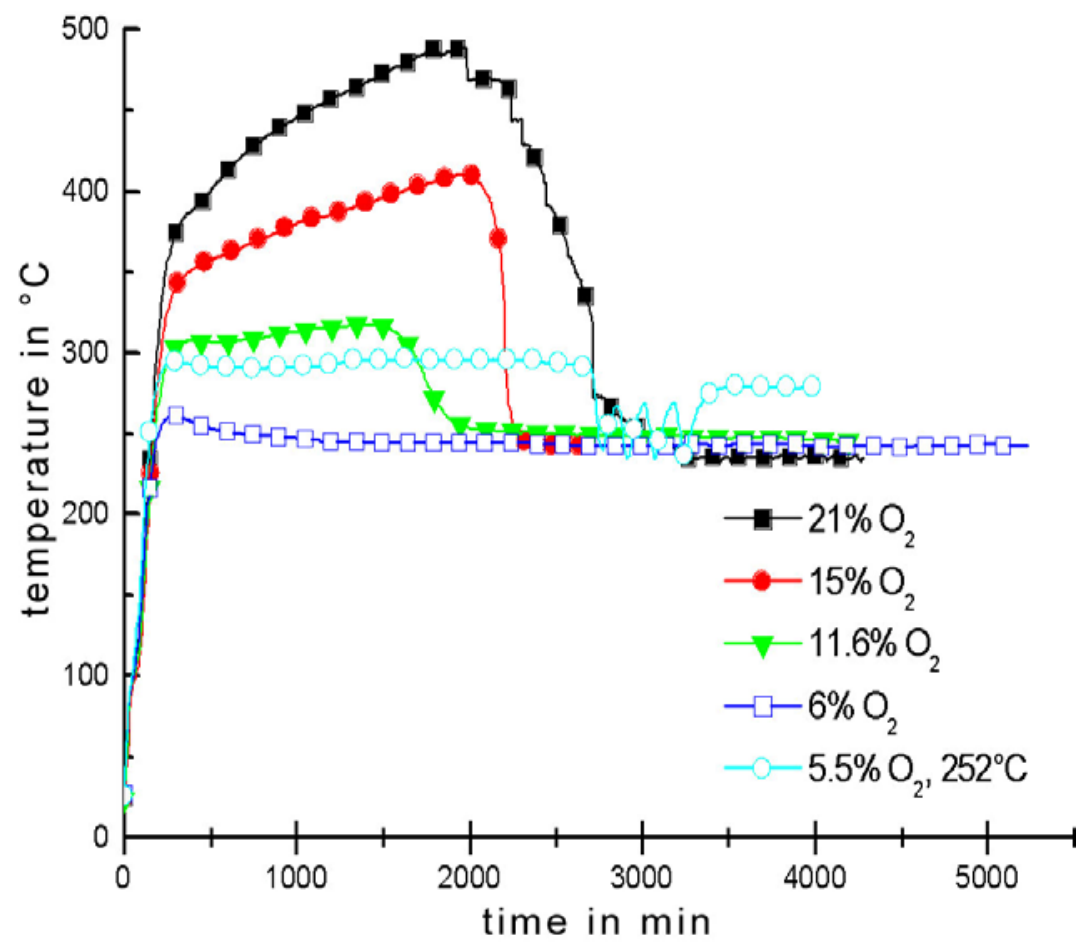

Fig. 7. Evolution of the temperature in the core of the $400 \mathrm{~mL}$ sample with time during self-ignition of black coal at different volume fractions of oxygen in the surrounding and at an oven temperature of $234^{\circ} \mathrm{C}$. (Symbols are not measured values but are intended to discriminate the different curves.) 


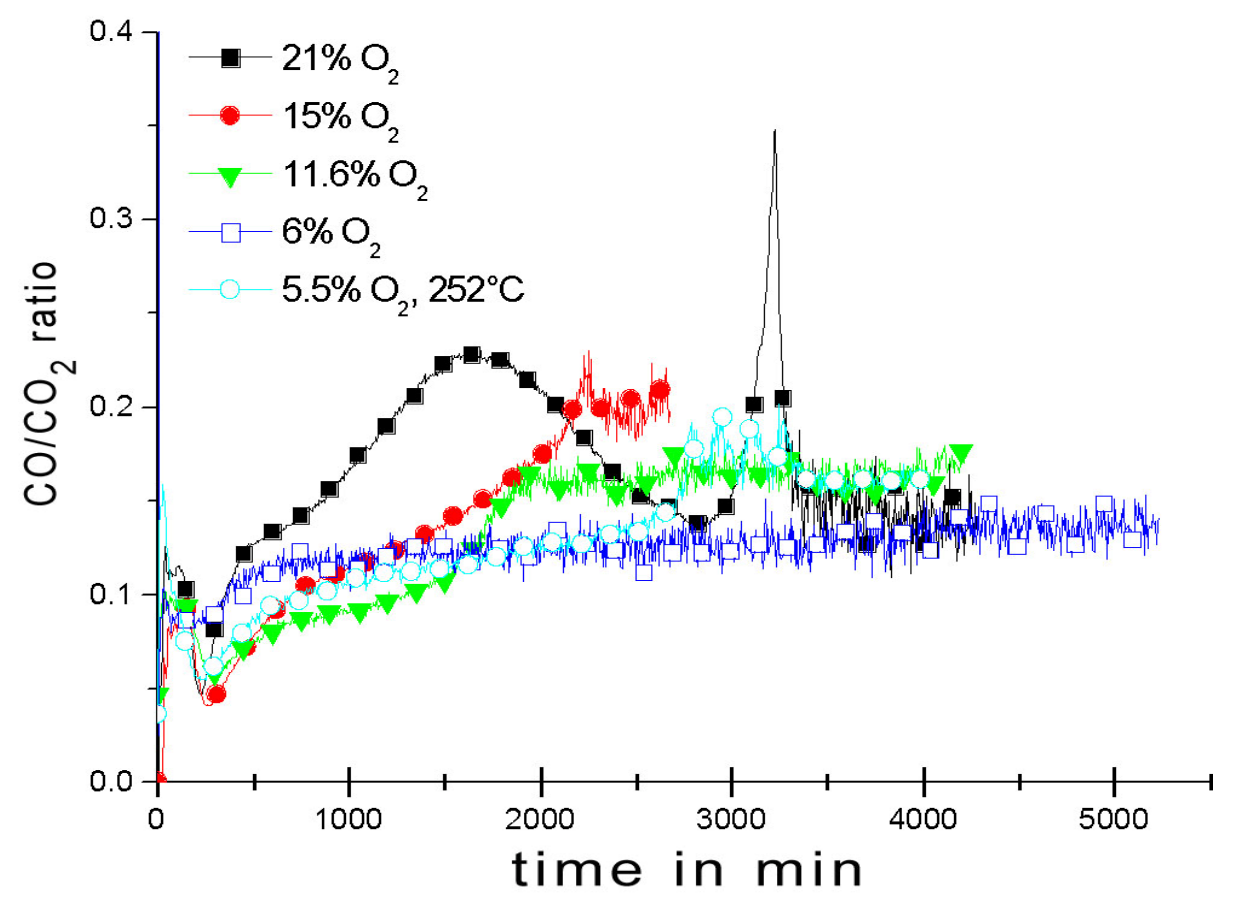

Fig. 8. Ratio of volume fractions of $\mathrm{CO}$ and $\mathrm{CO}_{2}$ for the combustion of $400 \mathrm{~mL}$ samples of black coal at different volume fractions of oxygen in the surrounding and at an oven temperature of $234{ }^{\circ} \mathrm{C}$. (Symbols are not measured values but are intended to discriminate the different curves.)

Figure 9 shows the temperature evolutions with time for the self ignition and smouldering of a $400 \mathrm{~mL}$ sample of lignite coal. Since the self-ignition temperature of the $400 \mathrm{~mL}$ sample of lignite was lower than for the other bulk materials, the oven temperature was reduced to $196^{\circ} \mathrm{C}$.

Again, the combustion was going the faster the higher the oxygen fraction in the flushing gas was. The reaction temperatures remained around $400{ }^{\circ} \mathrm{C}$ indicating that the reaction propagated as smouldering. The mass loss decreased from $95 \%$ for air to $90 \%$ for the gas mixture with $11.6 \%$ of oxygen. For the gas mixture with $6.7 \%$ of oxygen it was $80 \%$ and $50 \%$ for the gas mixture with $3.5 \%$ of oxygen.

The ratio of volume fractions of $\mathrm{CO}$ to $\mathrm{CO}_{2}$ for lignite is exhibited in fig. 10. In contrast to the black coal, for the lignite coal the highest ratio of $\mathrm{CO} / \mathrm{CO}_{2}$ was observed for the lowest oxygen concentration. However, for all oxygen concentrations the ratio of $\mathrm{CO} / \mathrm{CO}_{2}$ gradually decreased with the smouldering front propagating to the outer surface of the sample i.e. when the access of oxygen to the reaction zone was facilitated.

Figure 11 depicts the variation of the mass loss with the oxygen volume fraction for the four materials under investigation. For all materials the mass loss was the smaller the lower the oxygen volume fraction was. The only exception is the mass loss of black coal at $5.5 \%$ oxygen. In this experiment, however, the oven temperature was increased to $252{ }^{\circ} \mathrm{C}$ in order to achieve self-ignition at all, while it was $234{ }^{\circ} \mathrm{C}$ in the other experiments with black coal.

\section{CONCLUSIONS}

Experiments were performed to characterise the relation between reaction temperature, mass loss and ratio of $\mathrm{CO} / \mathrm{CO}_{2}$ in underventilated fires of bulk materials succeeding a self-ignition process. After ignition, the reaction propagated as smouldering in all experiments. A transition to glowing - indicated by reaction temperatures around $700{ }^{\circ} \mathrm{C}$ or higher did not occur.

As expected, the combustion was the faster the higher the volume fraction of oxygen in the gas flushing the inner chamber of the oven was. According to the reaction temperatures, the influence of oxygen fraction between $15 \%$ and $21 \%$ was significant only for black coal. 


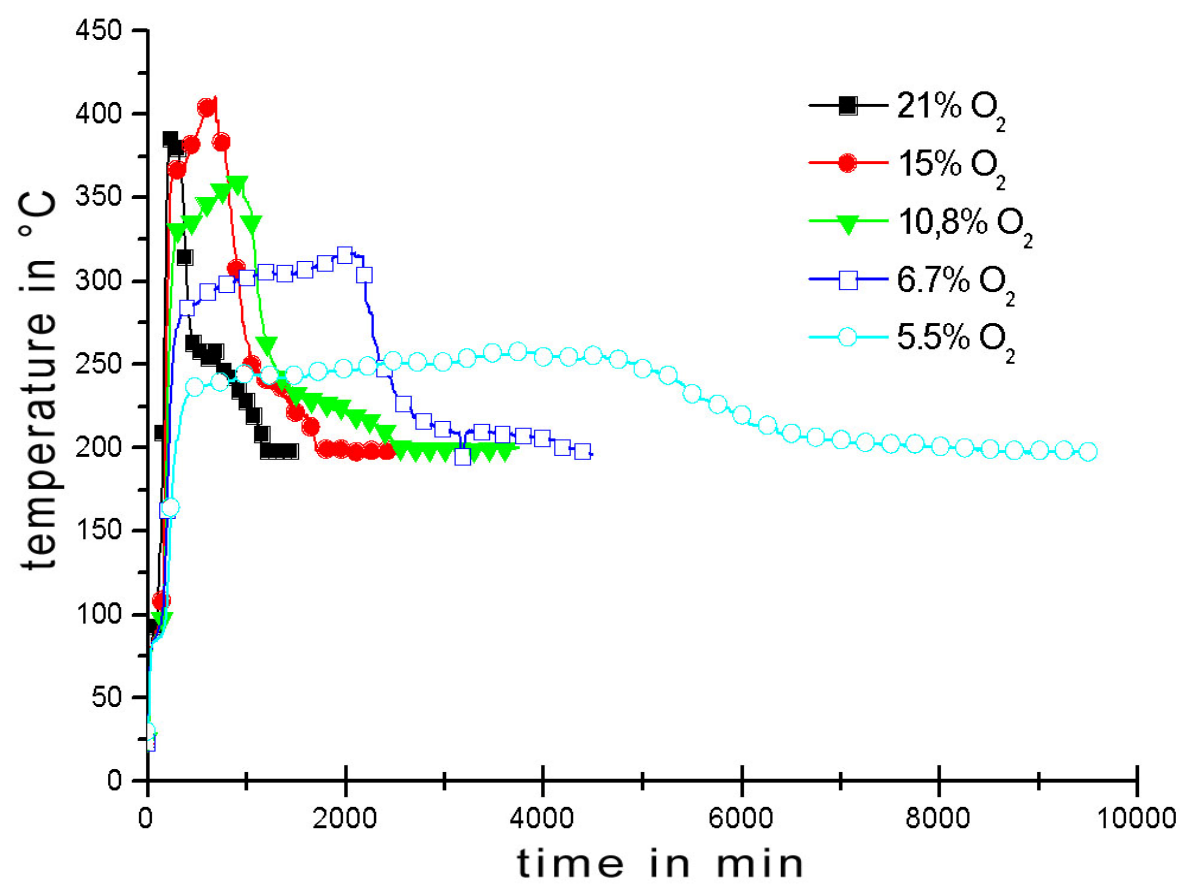

Fig. 9. Evolution of the temperature in the core of the $400 \mathrm{~mL}$ sample with time during self-ignition of lignite coal at different volume fractions of oxygen in the surrounding and at an oven temperature of 196 ${ }^{\circ} \mathrm{C}$. (Symbols are not measured values but are intended to discriminate the different curves.)

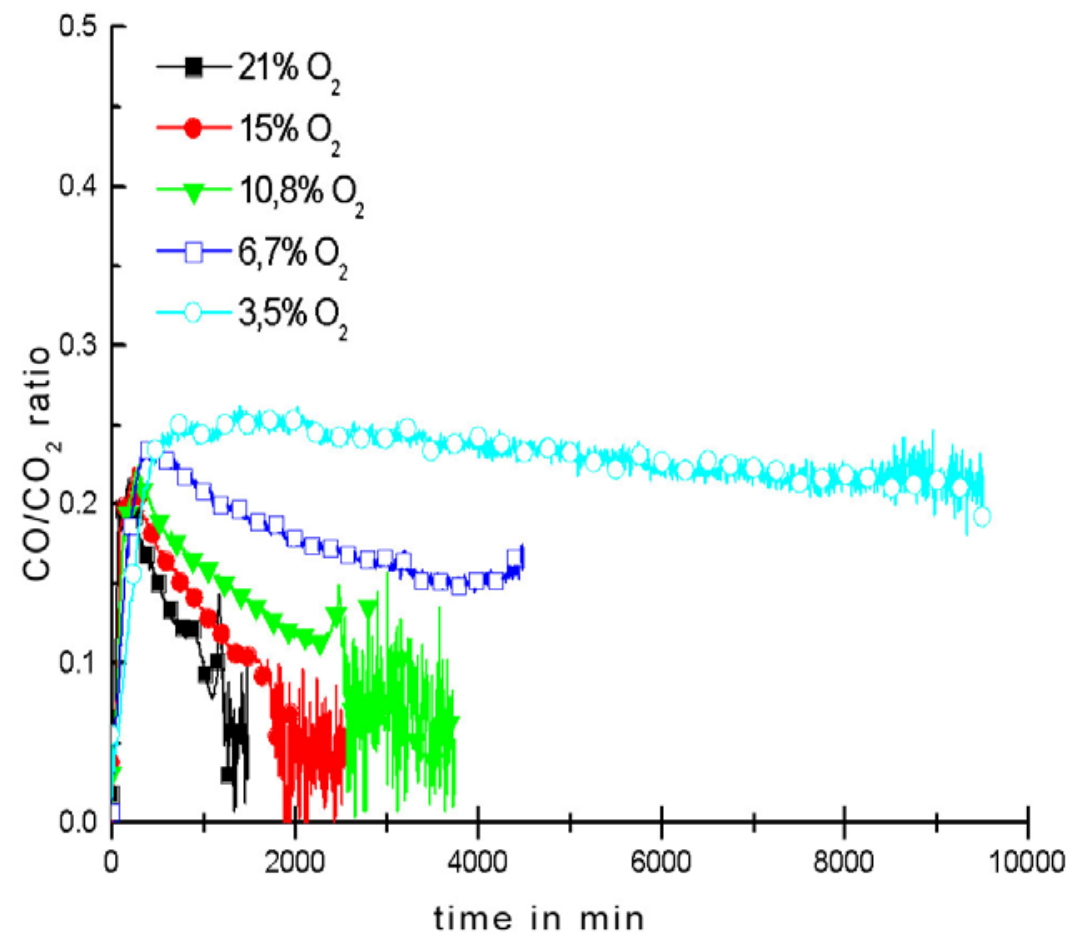

Fig. 10. Ratio of volume fractions of $\mathrm{CO}$ and $\mathrm{CO}_{2}$ for the combustion of $400 \mathrm{~mL}$ samples of lignite coal at different volume fractions of oxygen in the surrounding and at an oven temperature of $234{ }^{\circ} \mathrm{C}$. (Symbols are not measured values but are intended to discriminate the different curves.) 


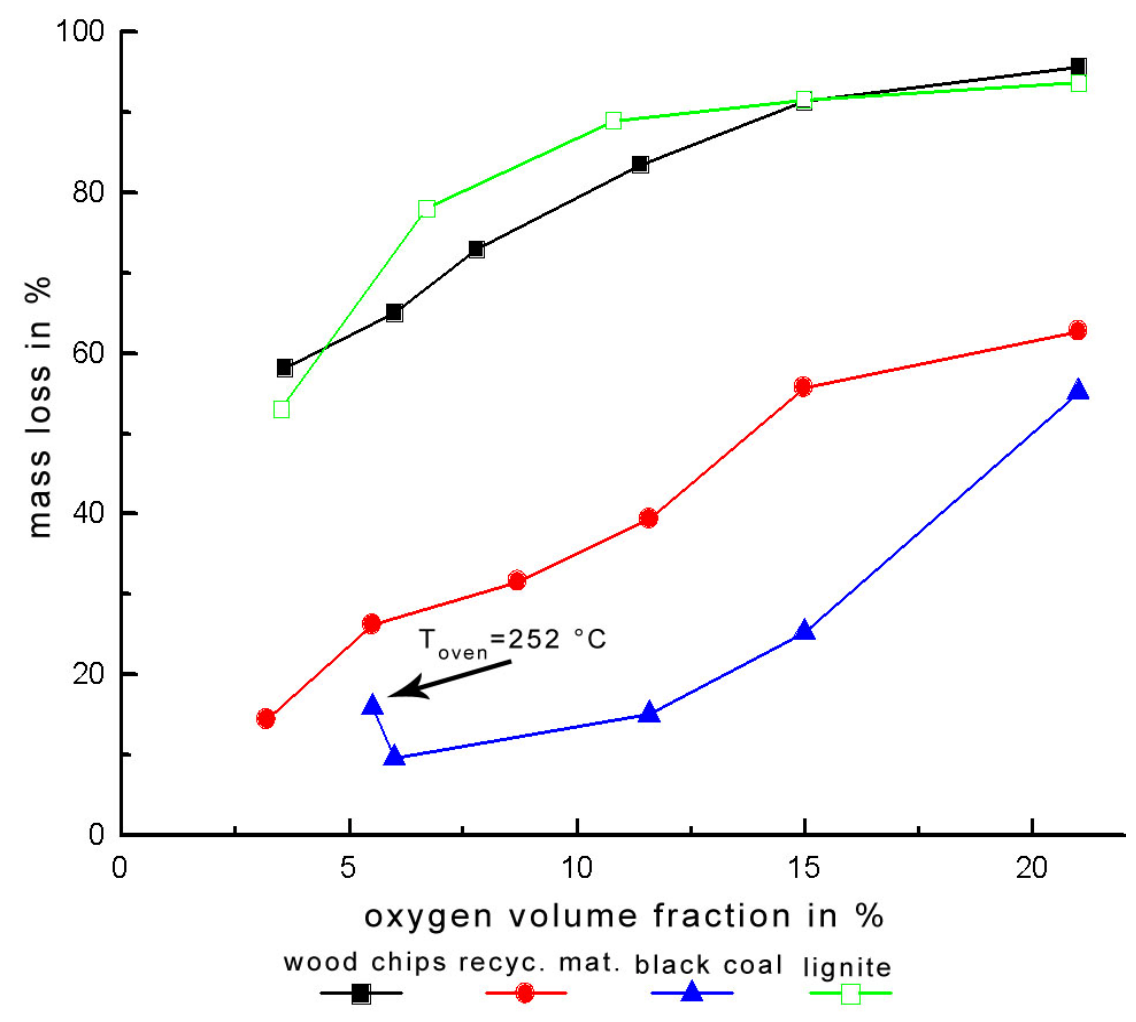

Fig.11. Variation of mass loss during smouldering with oxygen volume fraction for four bulk materials

Below this oxygen fraction the reaction temperatures decreased with decreasing oxygen fraction for all bulk materials investigated. This effect was also observed during fighting of silo fires where the reduction of the oxygen volume fraction by injecting inert gas lead to a significant decrease of the temperature of the flue gas.

Interestingly, the ratio of $\mathrm{CO} / \mathrm{CO}_{2}$ behaved differently for the different bulk materials. While for wood chips, for lignite coal and for the recycling material after ignition, i.e. during the propagation of smouldering the ratio of $\mathrm{CO} / \mathrm{CO}_{2}$ was the higher the lower the oxygen fraction in the flushing gas was, for black coal this ratio was highest when the sample was flushed with air.

A relevant production of $\mathrm{CH}_{4}$ could be measured only for wood chips and lignite coal. For wood chips the fraction of $\mathrm{CH}_{4}$ increased from $0.68 \%$ in volume at $6 \%$ volume fraction of oxygen to $1.86 \%$ at $21 \%$ of oxygen. For the lignite coal the volume fraction of $\mathrm{CH}_{4}$ increased from $0.08 \%$ at 11.6 volume fraction of oxygen to $0.42 \%$ at $21 \%$ of oxygen.

Summarising the results reported and comparing them to the corresponding case studies, it has to be stated that fires of bulk materials following self-ignition during storage occur as smouldering fires due to the limited availability of oxygen. Increased volume fractions of $\mathrm{CO}$ and $\mathrm{CO}_{2}$ are accompanying the fire together with an increased concentration of $\mathrm{H}_{2} \mathrm{O}$ with the exception of the black coal. With respect to early detection of such fires in storage facilities a combined detection of $\mathrm{CO}$ and $\mathrm{CO}_{2}$ may be a promising method. If other gases like $\mathrm{CH}_{4}$ or $\mathrm{H}_{2} \mathrm{O}$ are suitable indicators depends on the chemical composition of the bulk material stored.

It is out of the scope of this paper to present a theoretical approach to smouldering in bulk materials. Besides the pioneering modelling work of Ohlemiller [10], an attempt to simulate numerically such processes was made in [11]. In contrast to self-ignition, the subsequent propagation of smouldering through the bulk material does not depend on length scale. Instead, the rate of chemical conversion of the bulk material depends first of all on the availability of oxygen (as long as thermal decomposition of the material is of minor importance). Hence, provided those parameters determining the transportation of oxygen to the 
reaction sites (porosity, permeability, here expressed by the bulk density)are the same in lab scale and real scale, the results of the present study in terms of reaction temperatures, mass loss rates and combustion gas concentrations are directly convertible to real-scale applications. E.g. one has to expect that reducing the oxygen volume fraction in a burning silo to a level of, say, $5 \%$ by flushing it with inert gas will reduce the reaction temperature and the conversion rate, but it will not fully extinguish smouldering.

\section{REFERENCES}

1. Eckhoff R (1991) Dust Explosions in the Process Industries, Butterworth-Heinemann, Oxford

2. Humez A (1999), Feu de silo Magasins Generaux de France, Seminaire europeen sur les explosions de poussieres, 13.-15.04.1999, Metz, France (in French)

3. Westermann D (2008) Fire in a silo for wood pellets in Esbjerg, Denmark, 1998/1999 - a case study (to be published)

4. Bowes PC, Thomas PH (1966) Ignition and Extinction Phenomena Accompanying Oxygen-dependent Self-heating of Porous Bodies, Comb. Flame 10 pp.221-230, doi:10.1016/0010-2180(66)90078-2.

5. Schmidt M, Lohrer C, Krause U (2003) Self-ignition of dust at reduced volume fractions of ambient oxygen, J. Loss Prev. Process Ind. 16 (2003) 2, pp. 141-147

6. Gray BF, Wake CG(1990). The ignition of hygroscopic materials by water, Comb. Flame 79 2-6, doi:10.1016/0010-2180(90)90084-5.

7. Gray BF, Sexton MJ, Halliburton B, Macaskill C (2002), Wetting-induced ignition in cellulosic materials, Fire Safety Journal 37 465-479, doi:10.1016/S0379-7112(02)00002-4.

8. Li Vun Chon, Xiao Dong Chen (1999), A mathematical model of the self-heating of spray-dried food powders containing fat, protein, sugar and moisture, Chem. Eng. Science 54 pp. 4165-4178, doi:10.1016/S0009-2509(99)00115-3.

9. Poyda M (2007), Experimentelle Untersuchung der Zusammensetzung von Reaktionsprodukten der Selbstentzündung von fossilen und biogenen Brennstoffen, sowie von brennbaren Recyclingstoffen (Experimental investigation on the composition of reaction products of self-ignition of fossile and biofuels and combustible recycling products), Master thesis, University of Applied Sciences (FHTW), Berlin, (in German)

10. Ohlemiller TJ, Modelling of smouldering combustion propagation, Prog. Energy Comb. Sci. 11 (1985) pp. 277-310, doi:10.1016/0360-1285(85)90004-8.

11. Krause U, Schmidt M, Lohrer C (2006), A numerical model to simulate smouldering fires in bulk materials and dust deposits, Journal of Loss Prevention in the Process Industries, Vol. 19, pp 218-226, doi:10.1016/j.jlp.2005.03.005. 